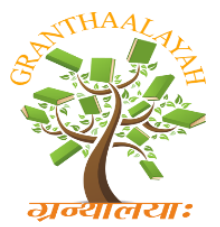

\author{
INTERNATIONAL JOURNAL OF RESEARCH - \\ GRANTHAALAYAH \\ A knowledge Repository
}

\title{
OPTIMIZATION OF WASTAGE PART OF COMPUTER SYSTEMS BY EFFECTIVE ACHIEVEMENT OF GREEN COMPUTING
}

\author{
Nirmala Gupta
}

Govt. Girls P.G College, Ujjain

\begin{abstract}
The environmental issues concerned with using computers because it is not possible to decrease the usage of computer. Our earth is also passing through the global warming, Green house effect and the ozone layer is becoming thin. Today Computers are widely used throughout the globe from any kind of organization to all over the place. The goals are to reduce the use of dangerous materials, maximize energy efficiency during the product's lifetime, and promote recyclability or biodegradability of useless products and factory waste.

It is to be known that as the economy expands, the demand for computing devices increases as business and individuals seek faster way of doing things - "The Computing way".

Keywords:

Green house effect, Green Computing, Optimization, recyclability.
\end{abstract}

\section{INTRODUCTION}

Green computing is like reducing the use of environmentally harmful materials like CFCs, promoting the use of recyclable materials, reducing the use of non-biodegradable components, and encouraging use of sustainable resources.

Many governments worldwide have initiated energy management programs. In 1998, the China National Development and Reform Commission (NDRC) founded the China Energy Conservation Program. In general, saving energy and saving resources saves money. The advantages of green technology are realized on both large and small scales. Many companies and business owners are hindered by the initially larger investment in the field of green technology, but fails to realize the long-term benefits and cost savings.

Possible Benefits: To minimize the energy consumption of computing resources during peak operation, harmful effects of computing resources and computing wastes uses eco-friendly sources of energy and save energy during idle operation.

Information and communication Technology products and service lifecycle, mostly as electricity but also in other forms such as gas and vehicle fuel. Many countries rely heavily on non-renewable energy sources, which are putting increasing pressure on a finite global resource especially in growing economies such as China and India. As a result of this inevitable surge in ICT-related GHG emissions, the industry is focusing most of its sustainability efforts on reducing emissions by improving energy efficiency.

One major approach in Green ICT is facilitate business functions from remote locations to reduce travel and in turn reduce the carbon footprint by substantially cutting down on Carbondioxide 
emissions caused by transport vehicles. Hundreds of millions of printer cartridges are purchased every year which end up in land fill. The cartridges themselves also use a range of chemicals in their manufacture, which leads out into the environment if not inclined of properly. They also contribute to the worlds growing e-waste problem.

\section{CHALLENGES}

The penalty of computer -waste or E-waste air pollution from processing hazardous and toxic materials can be dangerous to human health and Recycling uses large amounts of energy, generating Green House Gas emissions.

Moreover, if we can print less, print double sided or two to a page more often, share a printer with colleagues, use more environmentally sensitive paper and print equipment, we can reduce our ecological footprint, without affecting our quality of life. Even if videoconferencing is what most people think about when it comes to ICT's potential to save travel, we should also remember audioconferencing. In many situations a simple and working audio-conference system can save travel.

\section{CONCLUSION}

In Green Computing study and practice of designing, manufacturing, using, and disposing of computers, servers, and associated subsystems - such as monitors, printers, storage devices, and networking and communications systems - efficiently and effectively with minimal or no impact on the environment."

A new generation should be encouraged to develop similar skills using virtual meetings during their education and within the companies. People must be able to have meetings without other people being able to listen to conversations and it must be quick and simple to get a high quality.

\section{REFERENCES}

1. Social networking for business: Risk or ROI?, NZ Business, Sep 2010

2. Green Computing - a new Horizon of Energy Efficiency and Electronic waste minimization\|: a Global Perspective, Shalabh Agarwal and Asoke Nath : Proceedings of IEEE CSNT-2011 held at SMVDU(Jammu) 03-06 June 2011.

3. Green Computing is SMART COMPUTING - A Survey, Ms Swati Aggarwal, Mrs. Monika Garg, Mr. Pramod Kumar, International Journal of Engineering, Vol. 2, Issue 2, Feb 2012. [15] A Study on Green Computing:

4. A Study On Green Computing: The Future Computing And Eco- Friendly Technology S.V.S.S. Lakshmi1,

5. International Journal of Engineering Research andApplications (IJERA) ISSN: 2248-9622 Vol. 2, Issue4, July-August 2012 